\title{
Morphometric Analysis of the Inferior Vena Cava Related to Lumbar Vertebra and the Aortic Bifurcation on Multidetector Computed Tomography (MDCT)
}

\author{
Análisis Morfométrico de la Vena Cava Inferior Relacionado con las Vértebras Lumbares \\ en la Bifurcación Aórtica Mediante Tomografía Computadorizada Multidetector (TCMD)
}

\begin{abstract}
Elif Nedret Keskinoz; Ahmet Salbacak $^{* *}$; Duygu Akin ${ }^{* * * *}$; Anil Didem Aydin Kabakci***; Mehmet Tugrul Yilmaz ${ }^{* * *}$; Aynur Emine Cicekcibasi**** \& Orhan Ozbek*****
\end{abstract}

KESKINOZ, E. N.; SALBACAK, A.; AKIN, D.; KABAKCI, A. D. A.; YILMAZ, M. T.; CICEKCIBASI, A. E. \& OZBEK, O. Morphometric analysis of the inferior vena cava related to the lumbar vertebra and the aortic bifurcation on multidetector computed tomography (MDCT). Int. J. Morphol., 34(2):620-627, 2016.

SUMMARY: Vascular structures are in greater danger during lumbar surgery. The purpose of this study is to describe the morphology of the inferior vena cava (IVC) related to the lumbar vertebra and aortic bifurcation (AB) and assessing the role of demographic values in these relations to decrease the risk of complications in the surgical interventions. The study was performed on Multidetector Computed Tomography (MDCT) images of 100 male and 100 female cases with an age range from 50 to 84 years. The morphometric values of the IVC obtained from the coronal, sagittal and the axial reformatted images were measured and compared with the demographic values. The distance from the IVC to the $1^{\text {st }}$ lumbar vertebra (L1) and $2^{\text {nd }}$ lumbar vertebra (L2) were measured as (26.5 $\mathrm{mm}$ and $18.1 \mathrm{~mm}$ ) in males and $(21.1 \mathrm{~mm}$ and $14.2 \mathrm{~mm})$ in females with a high level of significance between genders; the distance from the IVC to the iliocaval confluence (IC), $3^{\text {rd }}$ lumbar vertebra (L3) and $4^{\text {rd }}$ lumbar vertebra (L4) were measured as $(6.5 \mathrm{~mm}, 10.5 \mathrm{~mm}$ and $6.9 \mathrm{~mm})$ in males and $(4.9 \mathrm{~mm}, 9.1 \mathrm{~mm}$ and $5.5 \mathrm{~mm})$ in females with significance between genders. The level of the IC was detected $46 \%$ of males, $39 \%$ of females at the level of lower third of L4. The vertical distance between the IC and the AB was measured and negative correlation between genders based on age was detected. Demographic values are important to consider the relationship of the IVC, the lumbar vertebra and the AB. The IVC was located further from the lumbar vertebra in males compared to females. Age increase played role in the approaching of the $\mathrm{AB}$ and the IC to each other in both gender and the IC to the promontory level in males.

KEY WORDS: Aortic bifurcation; Inferior vena cava; Iliocaval confluence; Lumbar vertebra; MDCT.

\section{INTRODUCTION}

The lumbar spine surgery is one of the surgical technique between one or more of the first lumbar and the first sacral vertebra (L1-S1). The most common lumbar spine surgeries include the lumbar fusion, disc arthroplasty, herniation and intradiscal electrothermal annuloplasty (Inamasu \& Guiot, 2006). The rate of lumbar spine surgery has increased since 80s even more in 90s (Malhotra et al., 2015; Weinstein et al., 2006). Radiological studies indicate that vascular structures such as the inferior vena cava (IVC) and the abdominal aorta (AA) have significant variability in their relation to the lumbar vertebra (Kleeman et al., 2002). Therefore, vascular structures are in greater danger and intraabdominal vascular injuries possibly even lead to death during these procedures (Asensio et al., 2000). Injuries that occur in the upper lumbar region between the second lumbar vertebra and the fourth lumbar vertebra (L2-L4) mainly cause damage to the AA and the IVC (Vaccaro et al., 2012).

Spine surgeries can be performed near the anterior, anterolateral (retroperitoneal) or posterior regions. Especially anterior spine surgery is a commonly accepted method, as it causes less morbidity compared to conventional surgery (Kornreich et al., 1998). However, vascular bleeding is the catastrophic complication associated with the anterior spine surgery. Although arterial injuries can be repaired by clamping, vascular injuries are difficult to repair and it needs

\footnotetext{
* Department of Anatomy, School of Medicine, Acibadem University, Istanbul, Turkey.

** Department of Anatomy, Faculty of Medicine, Ordu University, Ordu, Turkey.

**** Department of Anatomy, Meram Faculty of Medicine, Necmettin Erbakan University, Konya, Turkey.

***** Department of Radiology, Meram Faculty of Medicine, Necmettin Erbakan University, Konya; Turkey.
} 
grafting and ligation to control. Injury to sympathetic trunk is also other complication of this type of surgery (Vaccaro $\&$ Bono, 2007).

In this study, we aimed measuring the values of the morphometric data, such as distance and location of the IVC according to the lumbar vertebra, the aortic bifurcation $(\mathrm{AB})$ and the AA and comparing with the demographic values of sex, height, body weight and age.

\section{MATERIAL AND METHOD}

This study was performed on radiologic images, taken for various medical reasons (leukemia, colon cancer, acute pancreatitis, abdominal pain, liposarcoma etc.), of $200 \mathrm{ca}-$ ses (100 male and 100 female). Images were obtained using a 64-slice multidetector row CT machine. The cases with cardiovascular pathology, disc herniation and spinal disorders were excluded from the study. The study cases ranged in age from 50-84 years and their sex, height, weight and body mass index were recorded. The morphometric data in the axial, sagittal and the coronal sections were obtained. Ethical approval of the study was obtained from the NonInvasive Clinical Research Ethics Committee (ethical clearance number: 2013/480).

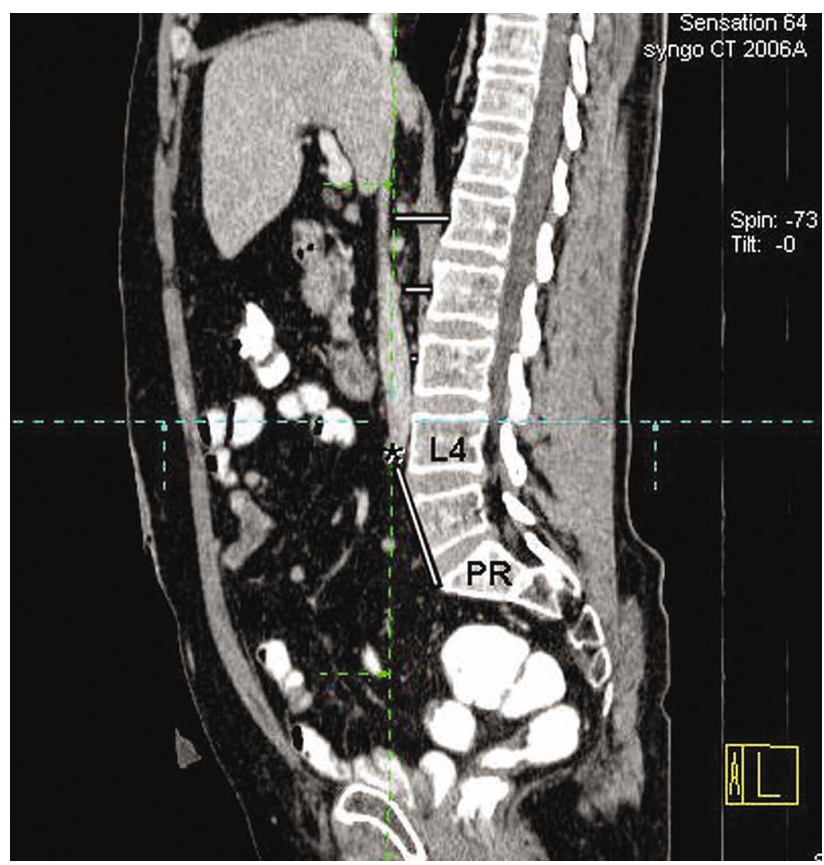

Fig. 1. Sagittal reformatted image (*indicates: Iliocaval confluence, Oblique line: The distance of the iliocaval confluence from the promontory level, Horizontal lines: The distance of the inferior vena cava from the lumbar vertebral body, L4= Fourth lumbar vertebra, $\mathrm{PR}=$ Promontory level).
After determining the iliocaval confluence (IC) as the confluence of the medial sides of the two common iliac veins, the following measurements were carried out. First, the distance between the posterior surface of the IC and the anterior surface of the lumbar vertebra (IVCilio) was horizontally measured on the sagittal reformatted image, after being identified the IC on the axial reformatted image (Figs. 1 and 2). In addition, the distance from the IVC to the first (IVC-L1), second (IVC-L2), third (IVC-L3) and the fourth lumbar vertebral body (IVC-L4) and the promontory level (IVC-PR) were measured in a manner similar to the previous measurement made (Fig. 1). The distance from the IVC to the fifth lumbar vertebral body (IVC-L5) was excluded because of the close proximity of the vessel and the vertebra. Third, vertical and vector distances between the IC and the $\mathrm{AB}$ were measured on the coronal reformatted image, after being identified on the axial reformatted image (Figs. 2-4). Oblique distance was measured as the vector distance between the IC and the $\mathrm{AB}$ (VeIC) (Fig. 3). To measure the vertical distance, a vertical line was drawn from the $\mathrm{AB}$ to the point where intersected with the horizontal line that was drawn from the IC. The height of the vertical line was identified as the vertical distance between the IC and the $\mathrm{AB}$ (VIC) (Fig. 4). Fourth, the level of the IC according to the lumbar vertebra (LeIC) was first identified on the sagittal reformatted image. Afterwards, that lumbar vertebra was divided into 3 parts (upper, middle and lower third) according to appearance of the transverse process on the axial reformatted image to determine the exact level of the IC (Figs. 1 and 2).

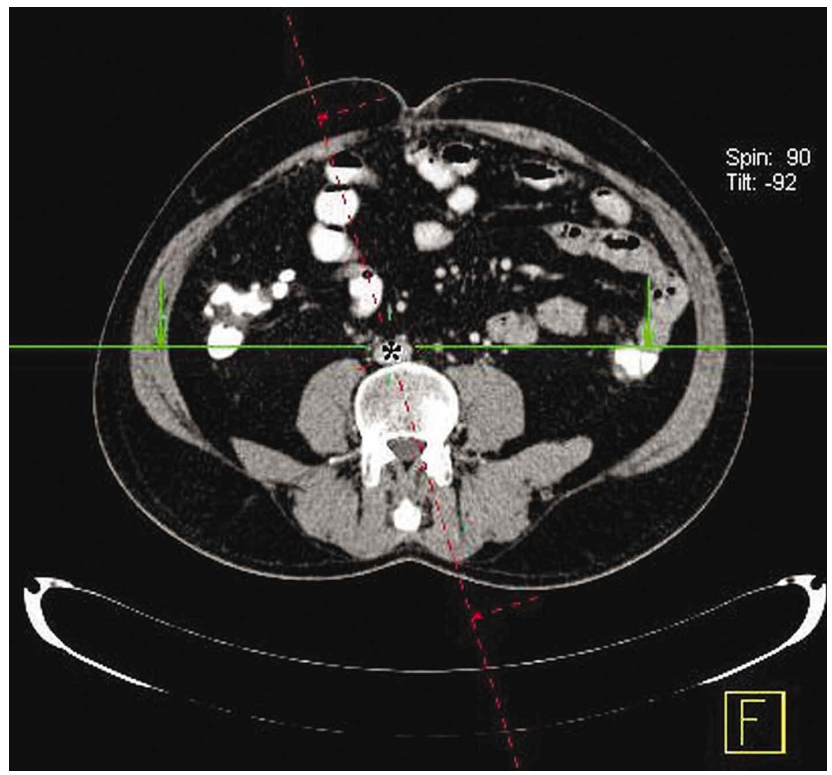

Fig. 2. Axial reformatted image was used for the measurement of the distance of the iliocaval confluence from the lumbar vertebra, the level of the iliocaval confluence according to the lumbar vertebra (* indicates: Iliocaval confluence) . 


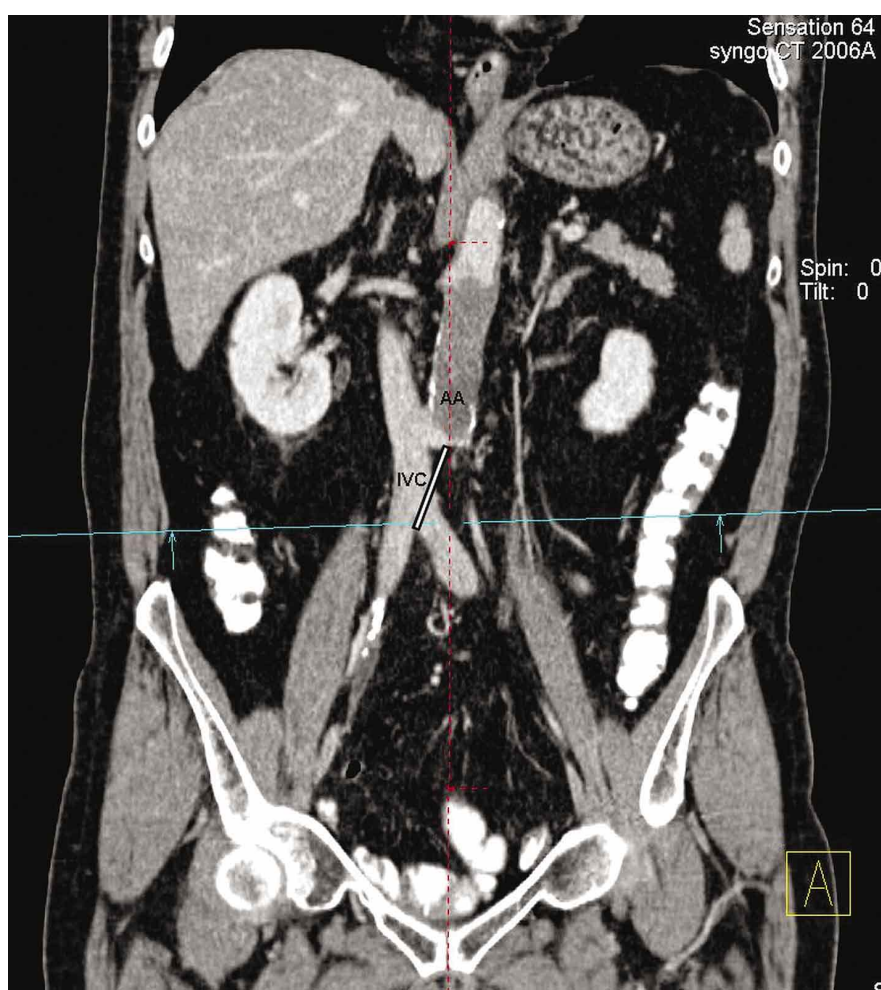

Fig. 3. Coronal reformatted image (IVC= Inferior vena cava, $\mathrm{AA}=\mathrm{Ab}-$ dominal aorta; Oblique line $=$ Vector distance between the iliocaval confluence and the aortic bifurcation).

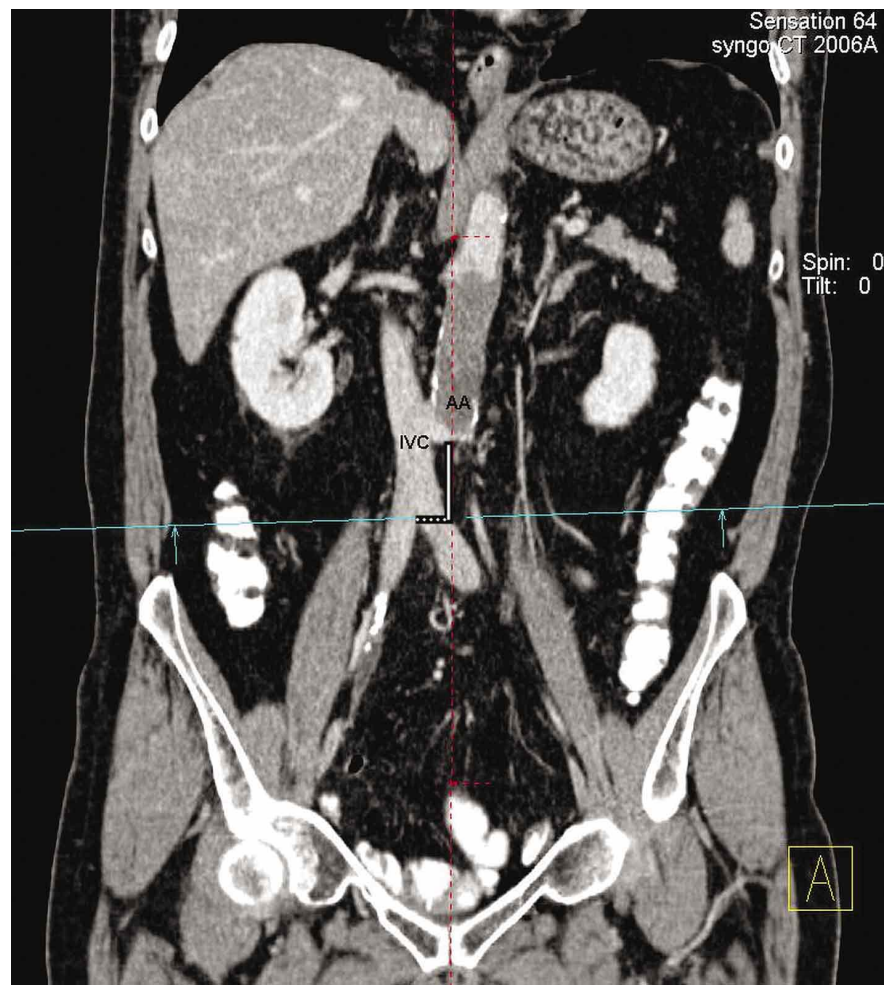

Fig. 4. Coronal reformatted image (IVC= Inferior vena cava, $\mathrm{AA}=\mathrm{Ab}-$ dominal aorta; Vertical line: Vertical distance between the iliocaval confluence and the aortic bifurcation).
The lumbar vertebra, identified as the level of the IC on the sagittal reformatted image, was also vertically divided into 3 parts (left, median and right third) on the coronal reformatted image to identify the localization of the IC according to the vertebral column (LoIC) (Figs. 1-3).

Lastly, the localization of the IVC was indicated as being on the right or left side of the AA (IAA) and the localization of the IC was indicated as being above, below or parallel with the AB (IAB) on the coronal reformatted image (Fig. 3). Finally, all data were entered into SPSS (Version 15.0).

\section{RESULTS}

The independent t-test was used to measure the demographic values of age, height and weight of the cases. According to results, the mean age of the cases were 62.09 \pm 7.82 in males (range 50-78) and 60.75 \pm 7.16 in females (range 50-84), height was $170.56 \pm 6.37 \mathrm{~cm}$ in males (range 155-195 cm) and $156.61 \pm 16.82 \mathrm{~cm}$ in females (range 145-175 cm) and weight was $74.7 \pm 13.24$ $\mathrm{kg}$ in males (range $47-120 \mathrm{~kg}$ ) and $74.83 \pm 12.21 \mathrm{~kg}$ in females (range 50-110 kg in females). The cases were divided into 3 different age groups (50-59, 60-69 and $\geq 70$ ). According to the SPSS frequency analysis, the percentage of the samples based on age groups was 41 $\%(n=82$; males, $n=38$, females, $n=44)$ for $50-59,44$ $\%(n=88$; males, $n=44$, females, $n=44)$ for $60-69$ and $15 \%(n=30$; males, $n=18$, females, $n=12)$ for $\geq 70$.

Minimum, maximum and mean values were calculated and the standard deviations of parameters (IVCilio, IVC-L1, IVC-L2, IVC-L3, IVC-L4, IVC-PR, VeIC and VIC) were determined. According to results, the mean values and standard deviations of parameters were $5.7 \pm 3.5 \mathrm{~mm}$ for IVCilio, $23.8 \pm 6.4 \mathrm{~mm}$ for IVC$\mathrm{L} 1,11.6 \pm 5.4 \mathrm{~mm}$ for IVC-L2, $9.8 \pm 4.3 \mathrm{~mm}$ for IVC-L3, $6.2 \pm 3.8 \mathrm{~mm}$ for IVC-L4, $62.3 \pm 15.7 \mathrm{~mm}$ for IVC-PR, $29.2 \pm 7.9 \mathrm{~mm}$ for VeIC and $20.0 \pm 9.0 \mathrm{~mm}$ for VIC (Table I).

The mean values, standard deviations and the significance levels of obtained data based on sex were evaluated using the independent t-test. It was determined that there were statistically high significant differences between measurements of males and females for IVCL1 and IVC-L2 (males: 26.5 and $18.1 \mathrm{~mm}$; females: 21.1 and $14.2 \mathrm{~mm}$ ), while statistically significant differences were present between the measurements of 
Table I. Mean values and inter-gender significance levels of the data obtained from all cases $(\mathrm{n}=$ total number of cases, Mean $\pm \mathrm{SD}=$ mean value \pm standard deviation, $\mathrm{p}=$ significance level, $\mathrm{mm}=$ millimeter).

\begin{tabular}{llccc}
\hline & Sex & n & Mean \pm SD $(\mathbf{m m})$ & p \\
\hline IVCilio & Male & 100 & $6.5 \pm 4.2$ & \\
& Female & 100 & $4.9 \pm 2.8$ & $0.030^{1}$ \\
& Total & 200 & $5.7 \pm 3.5$ & \\
IVC-L1 & Male & 100 & $26.5 \pm 7.0$ & \\
& Female & 100 & $21.1 \pm 5.9$ & $0.000^{2}$ \\
& Total & 200 & $23.8 \pm 6.4$ & \\
IVC-L2 & Male & 100 & $18.1 \pm 6.3$ & \\
& Female & 100 & $14.2 \pm 4.6$ & $0.000^{2}$ \\
& Total & 200 & $11.6 \pm 5.4$ & \\
IVC-L3 & Male & 100 & $10.5 \pm 4.6$ & \\
& Female & 100 & $9.1 \pm 4.0$ & $0.023^{1}$ \\
& Total & 200 & $9.8 \pm 4.3$ & \\
IVC-L4 & Male & 100 & $6.9 \pm 4.1$ & \\
& Female & 100 & $5.5 \pm 3.5$ & $0.012^{1}$ \\
& Total & 200 & $6.2 \pm 3.8$ & \\
IVC-PR & Male & 100 & $62.8 \pm 16.4$ & \\
& Female & 100 & $61.9 \pm 15.0$ & 0.679 \\
& Total & 200 & $62.3 \pm 15.7$ & \\
VeIC & Male & 100 & $29.6 \pm 8.6$ & \\
& Female & 100 & $28.8 \pm 7.3$ & 0.444 \\
VIC & Total & 200 & $29.2 \pm 7.9$ & \\
& Male & 100 & $20.8 \pm 10.1$ & \\
& Female & 100 & $19.3 \pm 7.7$ & 0.255 \\
& Total & 200 & $20.0 \pm 9.0$ & \\
\hline
\end{tabular}

$1=$ Statistically significant difference found using $\mathrm{p}<0.05$.

$2=$ Statistically high significant difference found using $\mathrm{p}<0.01$. males and females for IVCilio, IVC-L3 and IVC-L4 (males: $6.5,10.5$ and $6.9 \mathrm{~mm}$; females: $4.9,9.1$ and $5.5 \mathrm{~mm}$ ) (Table I).

The correlation analysis and significance levels were also evaluated between obtained data and demographic values (age, height and weight) based on sex using the SPSS correlation analysis. According to results, there were a statistically significant difference and a positive correlation between age and IVC-L4, negative correlations between age and IVC-PR and VIC, a statistically high significant difference and a negative correlation between age and VeIC in males, whereas a statistically high significant difference and a negative correlation between age and VIC in females.

A statistically high significant difference and a negative correlation between height and IVCilio in females were found.

Statistically high significant differences and positive correlations were found between weight and IVC-L2 and IVC-L3 in males, while statistically significant differences and positive correlations were found between weight and IVCilio and IVC-L3 in females (Table II).

In this study, LeIC was found to be at the level of the L3, L3-L4, L4, L4-L5, and L5 in $1 \%(\mathrm{n}=2), 10 \%(\mathrm{n}=20)$, $64 \%(\mathrm{n}=128), 16.5 \%(\mathrm{n}=33)$, and $8.5 \%(\mathrm{n}=17)$ cases,

Table II. The correlations between all the data obtained and the demographic values based on gender ( $\mathrm{n}=$ total number of cases, $\mathrm{r}=$ correlation, $\mathrm{p}=$ significance level).

\begin{tabular}{llccccccc}
\hline & & & \multicolumn{2}{c}{ Age } & \multicolumn{2}{c}{ Height } & \multicolumn{2}{c}{ Weight } \\
\cline { 5 - 9 } & Sex & $\mathbf{n}$ & $\mathbf{r}$ & $\mathbf{p}$ & $\mathbf{r}$ & $\mathbf{p}$ & $\mathbf{r}$ & $\mathbf{p}$ \\
\hline IVCilio & Male & 100 & -0.030 & 0.765 & -0.023 & 0.82 & 0.139 & 0.169 \\
& Female & 100 & 0.001 & 0.992 & $-0.257^{4}$ & 0.01 & 0.2253 & 0.024 \\
IVC-L1 & Male & 100 & 0.009 & 0.928 & 0.102 & 0.313 & 0.182 & 0.070 \\
& Female & 100 & -0.069 & 0.498 & -0.09 & 0.332 & 0.100 & 0.323 \\
IVC-L2 & Male & 100 & 0.082 & 0.416 & 0.176 & 0.080 & 0.3044 & 0.002 \\
& Female & 100 & 0.032 & 0.749 & -0.066 & 0.514 & 0.186 & 0.063 \\
IVC-L3 & Male & 100 & 0.182 & 0.071 & 0.135 & 0.182 & 0.3224 & 0.001 \\
& Female & 100 & -0.011 & 0.910 & 0.034 & 0.737 & 0.2113 & 0.035 \\
IVC-L4 & Male & 100 & 0.2083 & 0.038 & 0.104 & 0.302 & 0.171 & 0.090 \\
& Female & 100 & 0.010 & 0.920 & 0.050 & 0.618 & 0.153 & 0.128 \\
IVC-PR & Male & 100 & $-0.211^{3}$ & 0.035 & 0.120 & 0.234 & 0.186 & 0.064 \\
& Female & 100 & 0.036 & 0.719 & -0.024 & 0.811 & -0.028 & 0.785 \\
VeIC & Male & 100 & $-0.342^{2}$ & 0.000 & 0.090 & 0.373 & 0.099 & 0.327 \\
& Female & 100 & -0.132 & 0.192 & 0.164 & 0.103 & 0.014 & 0.888 \\
VIC & Male & 100 & $-0.221^{3}$ & 0.027 & 0.041 & 0.688 & 0.016 & 0.876 \\
& Female & 100 & -0.2784 & 0.005 & 0.102 & 0.313 & -0.104 & 0.302 \\
\hline
\end{tabular}

$3=$ Correlation is significant at the 0.05 level (2- tailed).

$4=$ Correlation is significant at the 0.01 level (2-tailed). 
Table III. The percentage values of the level of the iliocaval confluence according to the vertebral column (\%) ( $\mathrm{n}=$ number of cases).

\begin{tabular}{|c|c|c|c|c|c|c|c|c|c|c|c|c|}
\hline \multirow[b]{3}{*}{ Level of Ilıcaval Confluence } & \multicolumn{4}{|c|}{ Male } & \multicolumn{4}{|c|}{ Female } & \multicolumn{4}{|c|}{ All cases } \\
\hline & \multicolumn{2}{|c|}{ LeIC } & \multicolumn{2}{|c|}{ LeAB } & \multicolumn{2}{|c|}{ LeIC } & \multicolumn{2}{|c|}{ LeAB } & \multicolumn{2}{|c|}{ LeIC } & \multicolumn{2}{|c|}{ LeAB } \\
\hline & $\mathbf{n}$ & $\%$ & $\mathbf{n}$ & $\%$ & $\mathbf{n}$ & $\%$ & $\mathbf{n}$ & $\%$ & $\mathbf{n}$ & $\%$ & $\mathbf{n}$ & $\%$ \\
\hline Middle third of L3 & 0 & 0 & 1 & 1 & 0 & 0 & 3 & 3 & 0 & 0 & 4 & 2 \\
\hline Lower third of L3 & 1 & 1 & 11 & 11 & 1 & 1 & 15 & 15 & 2 & 1 & 26 & 13 \\
\hline L3-L4 & 10 & 10 & 11 & 11 & 10 & 10 & 19 & 19 & 20 & 10 & 30 & 15 \\
\hline Upper third of L4 & 5 & 5 & 21 & 21 & 15 & 15 & 20 & 20 & 20 & 10 & 41 & 20.5 \\
\hline Middle third of L4 & 9 & 9 & 30 & 30 & 14 & 14 & 23 & 23 & 23 & 11.5 & 53 & 26.5 \\
\hline Lower third of L4 & 46 & 46 & 19 & 19 & 39 & 39 & 14 & 14 & 85 & 42.5 & 33 & 16.5 \\
\hline L4-L5 & 17 & 17 & 5 & 5 & 16 & 16 & 2 & 2 & 33 & 16.5 & 7 & 3.5 \\
\hline Upper third of L5 & 8 & 8 & 1 & 1 & 1 & 1 & 4 & 4 & 9 & 4.5 & 6 & 3 \\
\hline Middle third of L5 & 2 & 2 & 1 & 1 & 3 & 3 & 0 & 0 & 5 & 2.5 & 0 & 0 \\
\hline Lower third of L5 & 2 & 2 & 0 & 0 & 1 & 1 & 0 & 0 & 3 & 1.5 & 0 & 0 \\
\hline Total & 100 & 100 & 100 & 100 & 100 & 100 & 100 & 100 & 200 & 100 & 200 & 100 \\
\hline
\end{tabular}

respectively. In order to confirm the reliability of the obtained results, the level of the $\mathrm{AB}$ according to the lumbar vertebra (LeAB) was determined in the same cases. Accordingly, LeAB was found to be at the level of the L3, L3-L4, L4, L4L5 and L5 in $15 \%(n=30), 15 \%(n=30), 63.5 \%(n=127)$, $3.5 \%(n=7)$ and $3 \%(n=6)$ of the cases, respectively. In totally LeIC was measured in $42.5 \%(n=85)$ of the samples at the lower third of the L4. The next common level of LeIC measured in $16.5 \%(n=33)$ of the samples was determined at the level of the L4-L5 disc space. The level of the AB (LeAB) was also measured and found at the middle third of the L4 in $26.5 \%(n=53)$ of the samples. The next common level of LeAB was found in $20.5 \%(n=41)$ of the samples at the level of the upper third of the L4 according to the SPSS frequency analysis (Table III).

LeIC and LeAB were determined separately in males and females. LeIC was most commonly seen at the lower third of the L4, being at the L4 in $60 \%$ (5 upper third, 9 middle third and 46 lower third) of males and $68 \%$ (15 upper third, 14 middle third and 39 lower third) of females in total; whereas LeAB was most commonly seen at the middle third of the L4, being at the L4 in $70 \%$ (21 upper third, 30 middle third and 19 lower third) of males, and $57 \%$ (20 upper third, 23 middle third and 14 lower third) of females in total (Table III).
LeIC and LeAB levels of individuals were also evaluated in 3 age groups $(50-59,60-69$ and $\geq 70)$ in order to determine if there was a relationship between LeIC/LeAB and age. In the measurements, LeIC was found in $32 \%$ of males and in $18 \%$ of females at the lower third of the L4 for the 50-59 age group, in $13 \%$ of males at the level of L4-L5 disc space and in $15 \%$ of females at the lower third of the L4 for the 60-69 age group, in $8 \%$ of males at the upper third of the L5 and in $6 \%$ of females at the lower third of the $\mathrm{L} 4$ for the $\geq 70$ age group (Table IV). LeAB was identified in $16 \%$ of males and in $11 \%$ of females at the middle third of the L4 and in $11 \%$ of females at the level of the the L3L4 disc space for the 50-59 age group, in $11 \%$ of males at the middle third of the L4 and in $12 \%$ of females at the lower third of the L3 for the 60-69 age group and in $9 \%$ of males at the lower third of the L4 and in $4 \%$ of females at the upper third of the $\mathrm{L} 4$ for the $\geq 70$ age group (Table V).

LoIC was found on the right third in $73.5 \%$ ( $\mathrm{n}=$ $147)$, on the left third in $0.5 \%(n=1)$ and on the median third of the vertebral column in $26 \%(n=52)$ of the samples according to the SPSS frequency analysis (Fig. 5). IAA was identified on the right side of the AA for all individuals. IAB was identified above in $1 \%(\mathrm{n}=2)$, parallel in $2 \%(\mathrm{n}=$ 4) and below in $97 \%(n=194)$ of the samples according to the SPSS frequency analysis.

Table IV. The comparison between the level of the iliocaval confluence and age group based on sex (\%).

\begin{tabular}{|c|c|c|c|c|c|c|c|c|c|c|}
\hline & & $\begin{array}{c}\text { Lower } \\
\text { Third of } \\
\text { L3 }\end{array}$ & L3-L4 & $\begin{array}{c}\text { Upper } \\
\text { Third of } \\
\text { L4 }\end{array}$ & $\begin{array}{c}\text { Middle } \\
\text { Third of L4 }\end{array}$ & $\begin{array}{c}\text { Lower } \\
\text { Third of } \\
\text { L4 }\end{array}$ & L4-L5 & $\begin{array}{c}\text { Upper } \\
\text { Third of L5 }\end{array}$ & $\begin{array}{c}\text { Middle } \\
\text { Third of } \\
\text { L5 }\end{array}$ & $\begin{array}{c}\text { Lower } \\
\text { Third of } \\
\text { L5 }\end{array}$ \\
\hline \multirow[t]{3}{*}{ Male } & $50-59$ & 1 & 4 & --- & --- & 32 & --- & --- & --- & --- \\
\hline & $60-69$ & --- & 6 & 5 & 9 & 12 & 13 & --- & --- & --- \\
\hline & $\geq 70$ & --- & --- & --- & --- & 2 & 2 & 8 & 2 & 2 \\
\hline \multirow[t]{3}{*}{ Female } & $50-59$ & 1 & 1 & 6 & 10 & 18 & 7 & --- & --- & 1 \\
\hline & $60-69$ & --- & 9 & 8 & 3 & 15 & 7 & 1 & 1 & --- \\
\hline & $\geq 70$ & --- & --- & 1 & 1 & 6 & 2 & --- & 2 & --- \\
\hline
\end{tabular}


Table V. The comparison between the level of the aortic bifurcation and age groups based on sex (\%).

\begin{tabular}{|c|c|c|c|c|c|c|c|c|c|c|}
\hline & & $\begin{array}{c}\text { Lower } \\
\text { Third of } \\
\text { L3 } \\
\end{array}$ & L3-L4 & $\begin{array}{c}\text { Upper } \\
\text { Third of } \\
\text { L4 } \\
\end{array}$ & $\begin{array}{l}\text { Middle } \\
\text { Third of L4 }\end{array}$ & $\begin{array}{c}\text { Lower } \\
\text { Third of } \\
\text { L4 }\end{array}$ & L4-L5 & $\begin{array}{c}\text { Upper } \\
\text { Third of L5 }\end{array}$ & $\begin{array}{c}\text { Middle } \\
\text { Third of } \\
\text { L5 }\end{array}$ & $\begin{array}{c}\text { Lower } \\
\text { Third of } \\
\text { L5 } \\
\end{array}$ \\
\hline \multirow[t]{3}{*}{ Male } & $50-59$ & 1 & 4 & 2 & 13 & 16 & 1 & --- & --- & 1 \\
\hline & $60-69$ & --- & 7 & 9 & 8 & 11 & 9 & 1 & --- & --- \\
\hline & $\geq 70$ & --- & --- & --- & --- & 3 & 9 & 4 & 1 & --- \\
\hline \multirow[t]{3}{*}{ Female } & $50-59$ & 2 & 3 & 11 & 9 & 11 & 7 & --- & 1 & --- \\
\hline & $60-69$ & 1 & 12 & 6 & 7 & 9 & 6 & 2 & 1 & --- \\
\hline & $\geq 70$ & --- & --- & 2 & 4 & 3 & 1 & --- & 2 & --- \\
\hline
\end{tabular}

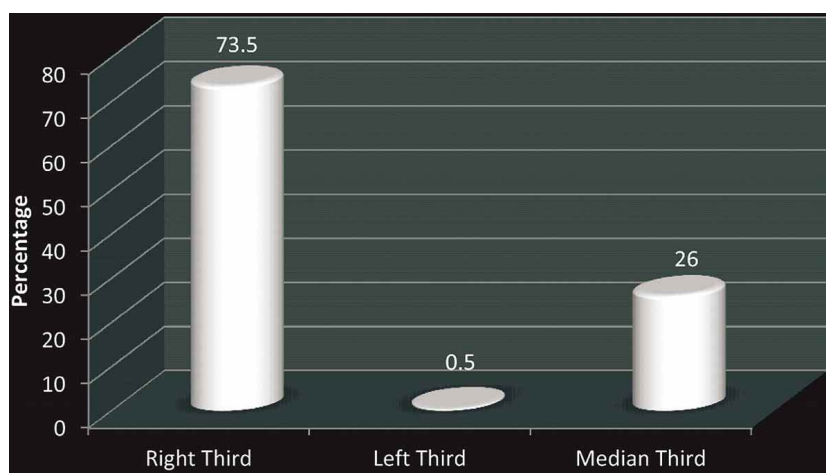

Fig. 5. The percentage values of localization of the iliocaval confluence according to the vertebral column (\%).

\section{DISCUSSION}

Degeneration of the lumbar vertebra and anatomic variations of the IVC lead to critical bleeding in the large vessels during anterior spinal surgery. Therefore, it is very useful to determine the location of large vessels and organs under the guidance of CT prior to surgical intervention (Koizuka et al., 2012). In this study, the anatomic details concerning the distance from the IVC to the lumbar vertebra were measured. The literature review revealed that no studies have been conducted on the distance between the IVC and the lumbar vertebra. According to values of the present study, it was determined that the distance between the IVC and the lumbar vertebra was increased as the IVC ascended upwards in both sex. The IVC was also located further from the vertebra in males compared to females. This could be attributed to the degeneration that occurs in the vertebra of females during the postmenopausal period. Additionally, the IC was also located further from the vertebra in short compared to tall females and fat compared to thin females. More studies need to be done to determine the reason of that result (Table I and II).

Lumbosacral fixation is the most common preferred method for lumbosacral pathologies. However, it leads to penetration of the anterior sacral cortex and damages to the neurovascular structures, due to failure to place the screw in the appropriate direction or at the appropriate depth. Ergur et al. (2007) performed an anatomic study on cadavers. The IC was reported to be above the promontory level, IVC-PR $39.4 \pm 10.6 \mathrm{~mm}$, in all male cases. Similarly, the IC was found to be above the promontory level, in all cases in the present study (Table I). Accordingly, age increase in males was determined to play a role in the approaching of the IC to the promontory level (Table II). As a result, it is believed that the greater distance from the IC to the promontory level compared with the previous study could be associated with acquiring the data from two different sexs and performing the measurements on MDCT images.

Kornreich et al. reported that the level of the IC descended from (L4-L5) to (L5-S1) due to age. Especially in older patients, the correlations of these veins and their distances between each other were of great importance during surgical interventions conducted at this level. VeIC was reported to be $19 \mathrm{~mm}$ by Pirró et al. (2005) and between 2 $\mathrm{mm}$ and $45 \mathrm{~mm}$ in 38 cases by Butoi et al. (2013). The measurement of VeIC was found similar to the previous studies (Table I). Although no study made about VIC was found during the literature review, it was measured so as to confirm the reliability of VeIC. According to our results, the $\mathrm{AB}$ and the IC were approached each other as the age increase (Table II). It is believed that this result could be associated with the degeneration occurring in the vertebra due to old age.

During anterior approach, large surgical area is required to access to the L5-S1 disc space and the scope of intervention is limited by the IC and the AB. This situation potentially leads to severe venous wounds that result in morbidity and death. Additionally, the risk of injuries increases due to anatomic variations (Madi et al., 2006). According to "Gray's Anatomy" and "Clinical Anatomy by Regions", LeIC is located in line with the L5 vertebra and just to the right of midline (Snell, 2008). According to other studies where one conducted by Danetz et al. (2003) LeIC reported to be at the following levels: L5-S1 disc space in $3.8 \%$, L5 vertebral body in $80.8 \%$, L4L5 disc space in $11.5 \%$, L4 vertebral body in $3.8 \%$; Koizuka et al. reported L3 vertebral body in 11 of 36 patients $(30.6$ $\%$ ); Appaji et al. (2014) reported L4 vertebral body in $60 \%$, 
$62.5 \%$ of which is at the lower border of L4 vertebral body and $20.83 \%$ at the upper border of L4 vertebral body, and $24 \%$ at the L4 vertebral body; Lakchayapakorn \& Siriprakarn (2008) reported L5 vertebral body in $69 \%$; Kawahara et al. (1996) reported L4-L5 disc space in $95 \%$ or L5 vertebral body; Capellades et al. (2000) reported L4 vertebral body in 4-21 \%; and Pirró et al. reported S1 vertebral body in $10 \%$. Our results were similar to the previous studies as the IC was determined at the lower third of $\mathrm{L} 4$ whereas the $\mathrm{AB}$ was seen at the middle third of L4. It is concluded that the IC was determined below the $\mathrm{AB}$ (Table III).

A diverse set of opinions has been put forward about the variability of the IC, including ones that ascribe this variability to the difference of population involved in the studies or to the fact that venous vessels have quite a lot of variations in the body compared to the arterial vessels or to the increased degeneration in the intervertebral disc due to aging, which leads to the shortening of vertebral column and the pulling of the IC and the AB levels downwards (Appaji et al.).

There are very few resources that show the differences of the IC in young and old cases. In a radiological study, MRI images of 134 patients with lower back pain were scanned, and LeIC was reported to vary according to age and sex (Capellades et al.). Other studies reported the following: Pirró et al. reported that LeIC of geriatric cases was located lower; Moussallem et al. (2012) reported that the IVC was prolonged with age and that caused changing of the level of the IC; and Kornreich et al. reported that this prolongation was more apparent in females. As specified in literature, it was concluded that both LeIC and LeAB of males were descended downwards due to old age, however, LeIC of females remained at the same level regardless of age, and LeAB of females was ascended first due to age and then was descended more apparently after the age of 60 . It is determined that no relation between the age and level of the IC found in females (Table IV and V). The reason behind this could be attributed to the individual differences in the rate of degeneration that occurs in vertebral column of females during the postmenopausal period. However, more studies must be conducted to make a final conclusion.

Besides, LoIC was monitored at the right third of all cases in the study by Pirró et al. and $60 \%$ of cases in the study by Lakchayapakorn \& Siriprakarn. Similar to these studies, LoIC was monitored at the right third in $73.5 \%$ of the cases in this study (Fig. 5).

In this study, IAB was found below the $\mathrm{AB}$ in 194 (97\%), parallel with the $\mathrm{AB}$ in $4(2 \%)$ and above the $\mathrm{AB}$ in $2(1 \%)$.
KESKINOZ, E. N.; SALBACAK, A.; AKIN, D.; KABAKCI, A. D. A.; YILMAZ, M. T.; CICEKCIBASI, A. E. \& OZBEK, O. Análisis morfométrico de la vena cava inferior relacionado con las vértebras lumbares en la bifurcación aórtica mediante tomografía computadorizada multidetector (TCMD). Int. J. Morphol., 34(2):620$627,2016$.

RESUMEN: Las estructuras vasculares corren gran peligro durante la cirugía lumbar. El propósito de este estudio fue describir la morfología de la vena cava inferior (VCI) en relación con las vértebras lumbares y la bifurcación aórtica (BA), junto con evaluar los valores demográficos de estas relaciones para disminuir el riesgo de complicaciones en las intervenciones quirúrgicas. Se utilizaron tomografías computadorizadas multidetector (TCMD) de 100 casos de hombres y mujeres entre 50 a 84 años de edad. Los valores morfométricos de la VCI se obtuvieron desde imágenes coronales y sagitales reformateadas, medidas y comparadas con los valores demográficos. Se midió la distancia de la VCI a la 1a (L1) y 2a vértebra lumbar (L2), en hombres de $26,5 \mathrm{~mm}$ y $18,1 \mathrm{~mm}$ respectivamente, y en mujeres de $21,1 \mathrm{~mm}$ y 14,2 $\mathrm{mm}$, respectivamente, con un alto nivel de significancia entre el sexos. La distancia desde la VCI a la confluencia iliocava (CI), 3a (L3) y 4a vértebra lumbar (L4) fue para los hombres de $6,5 \mathrm{~mm}, 10,5 \mathrm{~mm}$ y 6,9 $\mathrm{mm}$, respectivamente, y en mujeres de $4,9 \mathrm{~mm}, 9,1 \mathrm{~mm}$ y $5,5 \mathrm{~mm}$ respectivamente, con significancia entre los sexos. El nivel de la IC se detectó en $46 \%$ de los varones y en el $39 \%$ de las mujeres, a nivel de tercio inferior de L4. La distancia vertical entre la CI y la BA se tuvo una correlación negativa entre sexos en base a la edad. Los valores demográficos son importantes al considerar la relación de la VCI, las vértebras lumbares y la BA. La VCI se encuentra a una distancia mayor de las vértebras lumbares en hombres que en mujeres. El incremento de la edad jugó un papel importante en la aproximación de la BA y la IC, tanto entre sí como según sexo, con la CI a nivel del promontorio en los hombres.

PALABRAS CLAVE: Bifurcación aórtica; Vena cava inferior; Confluencia Iliocaval; Vertebra lumbar; TCMD.

\section{REFERENCES}

Appaji, A. C.; Kulkarni, R. \& Pai, S. B. Level of bifurcation of aorta and iliocaval confluence and its clinical relevance. IOSRJ Dent. Med. Sci., 13(7):56-60, 2014.

Asensio, J. A.; Chahwan, S.; Hanpeter, D.; Demetriades, D.; Forno, W.; Gambaro, E.; Murray, J.; Velmahos, G.; Marengo, J.; Shoemaker, W. C. \& Berne, T. V. Operative management and outcome of 302 abdominal vascular injuries. Am. J. Surg., 180(6):528-33; discussion 533-4, 2000.

Butoi, G.; Iliescu, D. M.; Baz, R. \& Bordei, P. Morphology of the terminal aorta. ARS Med. Tomitana, 19(2):61-6, 2013.

Capellades, J.; Pellisé, F.; Rovira, A.; Grivé, E.; Pedraza, S. \& Villanueva, C. Magnetic resonance anatomic study of iliocava junction and left iliac vein positions related to L5-S1 disc. Spine (Phila Pa 1976), 25(13):1695-700, 2000. 
KESKINOZ, E. N.; SALBACAK, A.; AKIN, D.; KABAKCI, A. D. A.; YILMAZ, M. T.; CICEKCIBASI, A. E. \& OZBEK, O. Morphometric analysis of the inferior vena cava related to the lumbar vertebra and the aortic bifurcation on multidetector computed tomography (MDCT). Int. J. Morphol., 34(2):620-627, 2016.

Danetz, J. S.; McLafferty, R. B.; Ayerdi, J.; Gruneiro, L. A.; Ramsey, D. E. \& Hodgson, K. J. Selective venography versus nonselective venography before vena cava filter placement: evidence for more, not less. J. Vasc. Surg., 38(5):928-34, 2003.

Ergur, I.; Akcali, O.; Kiray, A.; Kosay, C. \& Tayefi, H. Neurovascular risks of sacral screws with bicortical purchase: an anatomical study. Eur. Spine J., 16(9):1519-23, 2007.

Inamasu, J. \& Guiot, B. H. Vascular injury and complication in neurosurgical spine surgery. Acta Neurochir. (Wien), 148(4):375-87, 2006.

Kawahara, N.; Tomita, K.; Baba, H.; Toribatake, Y.; Fujita, T.; Mizuno, K. \& Tanaka, S. Cadaveric vascular anatomy for total en bloc spondylectomy in malignant vertebral tumors. Spine (Phila Pa 1976), 21(12):1401-7, 1996.

Kleeman, T. J.; Michael Ahn, U.; Clutterbuck, W. B.; Campbell, C. J. \& Talbot-Kleeman, A. Laparoscopic anterior lumbar interbody fusion at L4-L5: an anatomic evaluation and approach classification. Spine (Phila Pa 1976), 27(13):1390$5,2002$.

Koizuka, S.; Saito, S.; Masuoka, S.; Nakajima, K. \& Koyama, Y. Location of major vessels in prone-positioned patients undergoing percutaneous lumbar sympathectomy. Neuroradiology, 54(10):1127-31, 2012.

Kornreich, L.; Hadar, H.; Sulkes, J.; Gornish, M.; Ackerman, J. \& Gadoth, N. Effect of normal ageing on the sites of aortic bifurcation and inferior vena cava confluence: a CT study. Surg. Radiol. Anat., 20(1):63-8, 1998.

Lakchayapakorn, K. \& Siriprakarn, Y. Anatomical variations of the position of the aortic bifurcation, iliocava junction and iliac veins in relation to the lumbar vertebra. J. Med. Assoc. Thai., 91(10):1564-70, 2008.

Madi, K.; Aunoble, S.; Dehoux, E. \& Le Huec, J. C. Anatomic variations of the ilio-caval junction encountered in disk prosthesis implantation. Rev. Chir. Orthop. Reparatrice Appar. Mot., 92(2):112-7, 2006.

Malhotra, A.; Kalra, V. B.; Wu, X.; Grant, R.; Bronen, R. A. \& Abbed, K. M. Imaging of lumbar spinal surgery complications. Insights Imaging, 6(6):579-90, 2015.

Moussallem, C. D.; Abou Hamad, I.; El-Yahchouchi, C. A.; Moussallem, M. D.; Arnalsteen, D. M.; Mertl, P. \& Havet, E. Relationship of the lumbar lordosis angle to the abdominal aortic bifurcation and inferior vena cava confluence levels. Clin. Anat., 25(7):866-71, 2012.

Pirró, N.; Ciampi, D.; Champsaur, P. \& Di Marino, V. The anatomical relationship of the iliocava junction to the lumbosacral spine and the aortic bifurcation. Surg. Radiol. Anat., 27(2):137-41, 2005.
Snell, R. S. Clinical Anatomy by Regions. Philadelphia, Lippincott Williams \& Wilkins, 2008.

Vaccaro, A. R. \& Bono, C. M. Minimally Invasive Spine Surgery. New York, CRC Press, 2007.

Vaccaro, A. R.; Kepler, C. K.; Rihn, J. A.; Suzuki, H.; Ratliff, J. K.; Harrop, J. S.; Morrison, W. B.; Limthongkul, W. \& Albert, T. J. Anatomical relationships of the anterior blood vessels to the lower lumbar intervertebral discs: analysis based on magnetic resonance imaging of patients in the prone position. J. Bone Joint Surg. Am., 94(12):1088-94, 2012.

Weinstein, J. N.; Lurie, J. D.; Olson, P.; Bronner, K. K. \& Fisher, E. S. United States' trends and regional variations in lumbar spine surgery: 1992-2003. Spine (Phila Pa 1976), 31(23):270714,2006

Correspondance to:

Elif Nedret Keskinoz

Department of Anatomy, School of Medicine

Acibadem University

Kerem Aydinlar Kampusu, Icerenkoy Mahallesi

Kayisdagi Caddesi

No:32 Atasehir/ Istanbul 34758

TURKEY

Email: elifnedretguven@gmail.com

Received: 24-12-2015

Accepted: 06-04-2016 